\title{
O gênero Borreria (Spermacoceae, Rubiaceae) no estado do Ceará, Brasil
}

\author{
The genus Borreria (Spermacoceae, Rubiaceae) in the state of Ceará, Brazil
}

\author{
Francisco Álvaro Almeida Nepomuceno ${ }^{1,5}$, Elnatan Bezerra de Souza ${ }^{2}$, Izaíra Vasconcelos Nepomuceno ${ }^{2}$, \\ Laila Mabel Miguel ${ }^{3}$, Elsa Leonor Cabral ${ }^{3}$ \& Maria Iracema Bezerra Loiola ${ }^{4}$
}

\begin{abstract}
Resumo
O presente trabalho consiste do tratamento taxonômico de Borreria para a flora do Ceará. A partir de observações de campo e análise de materiais de herbário foram registradas 11 espécies: Borreria apodiensis, B. brownii, B. capitata, B. cupularis, B. latifolia, B. ocymifolia, B. scabiosoides, B. spinosa, B. tenella, B. verticillata e $B$. virgata. A maioria das espécies habita a vegetação de Caatinga e nove estão em Unidades de Conservação Ambiental. B. brownii, B. spinosa e B. verticillata são amplamente distribuídas nas unidades fitoecológicas do estado. Quatro espécies apresentam ocorrência mais restrita no Ceará: B. capitata e $B$. cupularis (na Chapada do Araripe), B. tenella (na Serra de Ubatuba e áreas adjacentes) e B. virgata (no Planalto da Ibiapaba). B. apodiensis é endêmica do Brasil, com distribuição restrita à Chapada do Apodi. Chave de identificação, descrições, imagens, dados de distribuição geográfica e habitat são apresentados.

Palavras-chave: Caatinga, Rubioideae, Semiárido, taxonomia.
\end{abstract}

\begin{abstract}
This work comprises the taxonomic treatment of genus Borreria for the Ceará flora. Based on field observations and herbaria specimens, eleven species were recorded: Borreria apodiensis, B. brownii, B. capitata, $B$. cupularis, B. latifolia, B. ocymifolia, B. scabiosoides, B. spinosa, B. tenella, B. verticillata and B. virgata. Most species occur in Caatinga vegetation and nine were registered in environmental conservation units. B. brownii, B. spinosa and B. verticillata are widely spread throughout the phytoecological units of the state. Four species have a more restricted occurrence in Ceará: B. capitata and B. cupularis (in the Araripe Plateau), B. tenella (in the Ubatuba Mountains and adjacent areas) and B. virgata (in the Ibiapaba Plateau). On the other hand, B. apodiensis is a endemic species to the Brazil, that is restricted to Chapada do Apodi. An identification key, descriptions, images, geographic distribution and habitat of the species are provided. Key words: Caatinga, Rubioideae, Semiarid, taxonomy.
\end{abstract}

\section{Introdução}

Borreria é um gênero pantropical com ca. 100 espécies, cujo centro de diversidade é na América do Sul (Miguel \& Cabral 2013; Miguel et al. 2015). No Brasil são registradas 70 espécies, das quais 31 são endêmicas (BFG 2015; Miguel et al. 2015; Souza et al. 2016). O gênero está representado em todas as unidades federativas e nos mais diversos tipos de vegetação que compõem o cenário fitoecológico brasileiro (BFG 2015). O planalto central brasileiro é o principal centro de diversidade, com destaque para a vegetação de Cerrado com 43 espécies catalogadas (BFG 2015; Miguel et al. 2015). Para a região Nordeste, são citadas 28 espécies, incluindo oito endêmicas,

\footnotetext{
${ }^{1}$ Universidade Federal de Pernambuco, Depto. Botânica, Centro de Biociências, Lab. Morfo-Taxonomia Vegetal (MTV), Av. Prof. Moraes Rego 1235, 50670901, Recife, PE, Brasil.

${ }^{2}$ Universidade Estadual Vale do Acaraú, Herbário Prof. Francisco José de Abreu Matos (HUVA), Av. da Universidade 850, 62040-370, Sobral, CE, Brasil.

${ }^{3}$ Universidad Nacional del Nordeste (UNNE), Instituto de Botánica del Nordeste (IBONE-CONICET), Sargento Cabral 2131, c.c. 209, 3400, Corrientes, Argentina.

${ }^{4}$ Universidade Federal do Ceará, Depto. Biologia, Lab. Sistemática e Ecologia Vegetal (LASEV), bl. 906, Campus do Pici, 60440-900, Fortaleza, CE, Brasil.

${ }^{5}$ Autor para correspondência: alvaronepomuceno567@gmail.com
} 
sendo o estado da Bahia (25 spp.) o que apresenta o maior número de registros (BFG 2015; Souza et al. 2016).

Dentre os gêneros da tribo Spermacoceae sensu stricto (Robrecht 1988), Borreria possui o maior número de espécies. O gênero se caracteriza por apresentar cápsulas com deiscência longitudinal e ambas as valvas deiscentes (ex., B. spinosa Cham. \& Schltdl. ex DC.), ambas indeiscentes [ex., B. verticillata (L.) G. Mey. ] ou uma valva deiscente e outra parcialmente deiscente [ex., $B$. ocymifolia (Roem. \& Schult.)] Bacigalupo \& E.L. Cabral) (Bacigalupo \& Cabral 1996). Devido à similaridade morfológica entre os gêneros da tribo, especialmente em relação às folhas, bainha estipular e inflorescências, espécimes de Borreria são facilmente confundidos com representantes de Diodia L., Hexasepalum Bartl. ex DC., Mitracarpus Zucc. ex Schult. \& Schult. f., Spermacoce L., Staelia Cham. \& Schltdl. e Richardia L.

A delimitação entre Borreria e Spermacoce continua incerta e estudos moleculares que incluam uma maior amostragem de espécies americanas são necessários para definir as relações filogenéticas entre esses gêneros. Alguns autores consideram as espécies americanas de Borreria inseridas no conceito de Spermacoce sensu lato (Burger \& Taylor 1993; Delprete \& Cortés 2006; Delprete 2007, 2010; Delprete et al. 2012). Porém, outros pesquisadores mantiveram ambos os gêneros separados, com base em dados carpológicos, polínicos e de sementes (Bacigalupo \& Cabral 1996; Bacigalupo et al. 2010; Cabral et al. 2010; Cabral et al. 2011). Recentemente, Florentin et al. (2016) realizaram a transferência de Borreria sect. Pseudodiodia Hassl. para o gênero Spermacoce, por compartilharem estames inclusos e fixos na base do tubo ou na porção mediana da fauce da corola, estigmas inclusos e grãos de pólen subprolatos ou prolato-esferoidais, com colpos largos, exina tectada com microespinhos distribuídos ao redor da ectoabertura (Tipo I, segundo Pire 1996). Morfologicamente, táxons americanos de Borreria são diferenciados de Spermacoce pelos estames e estigmas exsertos, e grãos de pólen esferoidais ou oblato-esferoidais, colporados, colpados com endocíngulo ou porados (Florentin et al. 2016).

Devido principalmente à semelhança das folhas e flores, este gênero apresenta uma complexidade taxonômica, e os estudos focando os representantes de Borreria no Brasil são escassos. Os trabalhos registrados na literatura concentrados nos representantes do gênero no Brasil foram:
Melo e Barbosa (2007), que listaram três espécies de Borreria para uma área de restinga na Paraíba; Cabral et al. (2011) catalogaram 29 espécies no estado da Bahia, onde duas foram novas para a Ciência: B. catolensis E.L. Cabral \& L.M. Miguel e B. diamantinae R.M. Salas \& E.L. Cabral, sendo este o principal estudo para o gênero no país. No ano seguinte, Cabral et al. (2012) propuseram mais duas novas espécies: $B$. carajasensis E.L. Cabral \& L.M. Miguel e B. elaiosulcata E.L. Cabral \& L.M. Miguel, ocorrentes na Serra de Carajás e relataram o primeiro registro de $B$. cupularis DC e B. multiflora (DC.) Bacigalupo \& E.L. Cabral, no estado do Pará. Neste mesmo estudo, os autores ainda elaboraram uma chave para as espécies de Borreria com sementes transversalmente sulcadas ocorrentes na América do Sul, reconhecendo 11 táxons. Recentemente, Miguel et al. (2015), publicaram duas espécies novas, B. minensis E.L. Cabral, L.M. Miguel \& E.B. Souza, para Minas Gerais, e B. psyllocarpoides E.L. Cabral \& L.M. Miguel, para Goiás e Minas Gerais. Já Souza et al. (2016), descreveram B. apodiensis E.L. Cabral, L.M. Miguel \& E.B. Souza, para os estados do Ceará e Rio Grande do Norte.

O presente trabalho é parte de um estudo mais amplo sobre as Rubiaceae para a flora do Ceará e teve como objetivo inventariar e descrever as espécies de Borreria ocorrentes no estado, contribuindo para ampliação do conhecimento sobre a distribuição geográfica das espécies e consequentemente para a diversidade da flora brasileira.

\section{Material e Métodos}

Área de estudo

O estado do Ceará possui uma área com aproximadamente $148.825,6 \mathrm{~km}^{2}$, equivalente a $1,74 \%$ do território nacional e $9,57 \%$ da região Nordeste (IPECE 2013). Ao norte limita-se com o Oceano Atlântico, ao leste com os estados do Rio Grande do Norte e Paraíba, ao sul com Pernambuco e a oeste com o Piauí (IPECE 2013).

De acordo com Moro et al. (2015), o Ceará possui dois grandes domínios geológicos, um de origem sedimentar e outro de origem cristalina, divididos em oito unidades geológicas, sendo seis sedimentares (Planície Litorânea, Planícies Fluviais, Tabuleiros Costeiros, Chapada do Apodi, Serra da Ibiapaba e Chapada do Araripe) e duas cristalinas (Maciços Residuais e Depressão Sertaneja) e 11 unidades fitoecológicas: Complexo 
Vegetacional Costeiro (Matas de restinga), Floresta Perenifólia Paludosa Marítima (Mangue), Floresta Subcaducifólia Tropical Xeromorfa (Cerradão), Cerrado, Floresta Mista Dicótilo-Palmácea (Mata Ciliar), Floresta Subcaducifólia Tropical Pluvial do Cristalino (Matas Secas do Cristalino), Floresta Subcaducifólia Tropical Pluvial do Sedimentar (Matas Secas do Sedimentar), Floresta Subperenifólia Tropical Plúvio-Nebular do Cristalino (Matas Úmidas do Cristalino), Floresta Subperenifólia Tropical Plúvio-Nebular do Sedimentar (Matas Úmidas do Sedimentar), Floresta Caducifólia Espinhosa do Cristalino (Caatinga do Cristalino) e Floresta Caducifólia Espinhosa do Sedimentar (Caatinga do Sedimentar) que estão distribuídas irregularmente ao longo de toda extensão territorial do estado (Fig. 1).

Estudos em campo e laboratório - Foram analisados espécimes do gênero Borreria provenientes de expedições de coletas realizadas entre março de 2010 e junho de 2016, e coleções depositadas nos herbários CTES, EAC, HUVA, HUEFS e HCDAL (acrônimos de acordo com Thiers cont. updated). Os materiais foram coletados seguindo a metodologia de Mori et al. (1989) e posteriormente incorporados no acervo do herbário HUVA. Duplicatas foram enviadas para os herbários CTES, EAC e HUEFS. A identificação foi realizada com auxílio de chaves analíticas, por comparação com espécimes de herbários e através do site Lista de Espécies da Flora do Brasil (<http://floradobrasil.jbrj.gov.br $>)$ e literatura especializada (Bacigalupo \& Cabral 1996, 1999; Cabral \& Bacigalupo 1996, 1999; Delprete 2007, 2010; Cabral et al. 2011; Delprete et al. 2012).

A terminologia dos caracteres morfológicos seguiu Radford et al. (1974), Robbrecht (1988) e Gonçalves \& Lorenzi (2011). Os nomes científicos das espécies estão de acordo com o IPNI (2016). Informações sobre hábito e habitat das espécies estão baseadas em dados de herbário e nas observações de campo. Aspectos ecológicos seguem a terminologia adotada pelo Manual Técnico da Vegetação Brasileira (IBGE 2012).

A distribuição geográfica das espécies reflete as informações contidas nas etiquetas das exsicatas, literatura especializada (Bacigalupo \& Cabral 1996, 1999; Cabral \& Bacigalupo 1996, 1999; Cabral et al. 2006, 2011; Delprete 2007, 2010; Delprete et al. 2012; Miguel \& Cabral 2013; Miguel et al. 2015; Souza et al. 2016), e na Lista de Espécies da Flora do Brasil (BFG 2015).

\section{Resultados e Discussão}

\section{Tratamento taxonômico}

Borreria G. Mey., * Prim. Fl. Esseq. 79. 1818.

Ervas a subarbustos, anuais ou perenes; ramos cilíndricos a tetrágonos, glabros, pubescentes ou pilosos, com ou sem alas. Estípulas invaginantes e fimbriadas, bainha estipular glabra, pubescente, pubérula ou pilosa, setas filiformes, lineares ou estreito-triangulares, glabras, pubescentes ou pilosas, com ou sem coléter apical (Fig. 2a-b). Folhas opostas ou pseudoverticiladas pela presença de braquiblastos, sésseis ou pseudopecioladas, lâmina elíptica, estreito-elíptica, linear, ovada ou estreitoovada, ápice agudo, acuminado ou cuspidado, base atenuada ou cuneada, membranácea, cartácea, papirácea ou raramente subcoriácea, glabra, glabrescente, pubérula, pubescente, pilosa, ou raramente hirsuta, escabra ou estrigosa, margem plana ou revoluta, escabra, ciliada ou glabra, nervuras secundárias conspícuas ou inconspícuas, plicadas ou não. Inflorescências terminais e/ou axilares, 1-22 glomérulos por ramo, hemisféricos, globosos ou subglobosos, subtendidos por 2-12(16) brácteas foliáceas. Flores sésseis ou subsésseis, hipanto geralmente turbinado ou obcônico; cálice 2(-3)4-mero, lobos geralmente iguais, lineares, estreito-triangulares ou ovados, glabros, pilosos a ciliados na margem; corola 4-mera, campanulada, subhipocrateriforme, ciatiforme ou infundibuliforme, alva, rosada, lilás ou azulada; tubo externamente glabro a diminutamente papilado e internamente com 1 anel de tricomas na metade do tubo; lobos glabros ou pilosos, valvados na prefloração; estames 4, exsertos, comprimento e forma dos filetes pouco variável, anteras oblongas, dorsifixas, alvas, cremes, azuladas ou acinzentadas; estilete exserto, filiforme, comprimento pouco variável, estigma capitado, bilobado, bífido ou curtamente bífido; disco nectarífero bipartido ou inteiro, comprimento e largura pouco variável (Fig 2c-e). Fruto capsular com deiscência longitudinal, separando-se parcialmente em duas valvas, ambas as valvas deiscentes, parcialmente deiscente ou indeiscente, elipsoides, oblongoides, ovoides ou obcônicas (Fig. 2f-h). Sementes elipsoides, ovoides ou oblongoides, castanhas a negras, face dorsal com ou sem sulcos transversais ou estrias transversais, fovéolo-reticuladas ou suavemente reticuladas e encaixe ventral com sulco longitudinal amplo

\footnotetext{
* Descrição baseada nas espécies do Ceará
} 


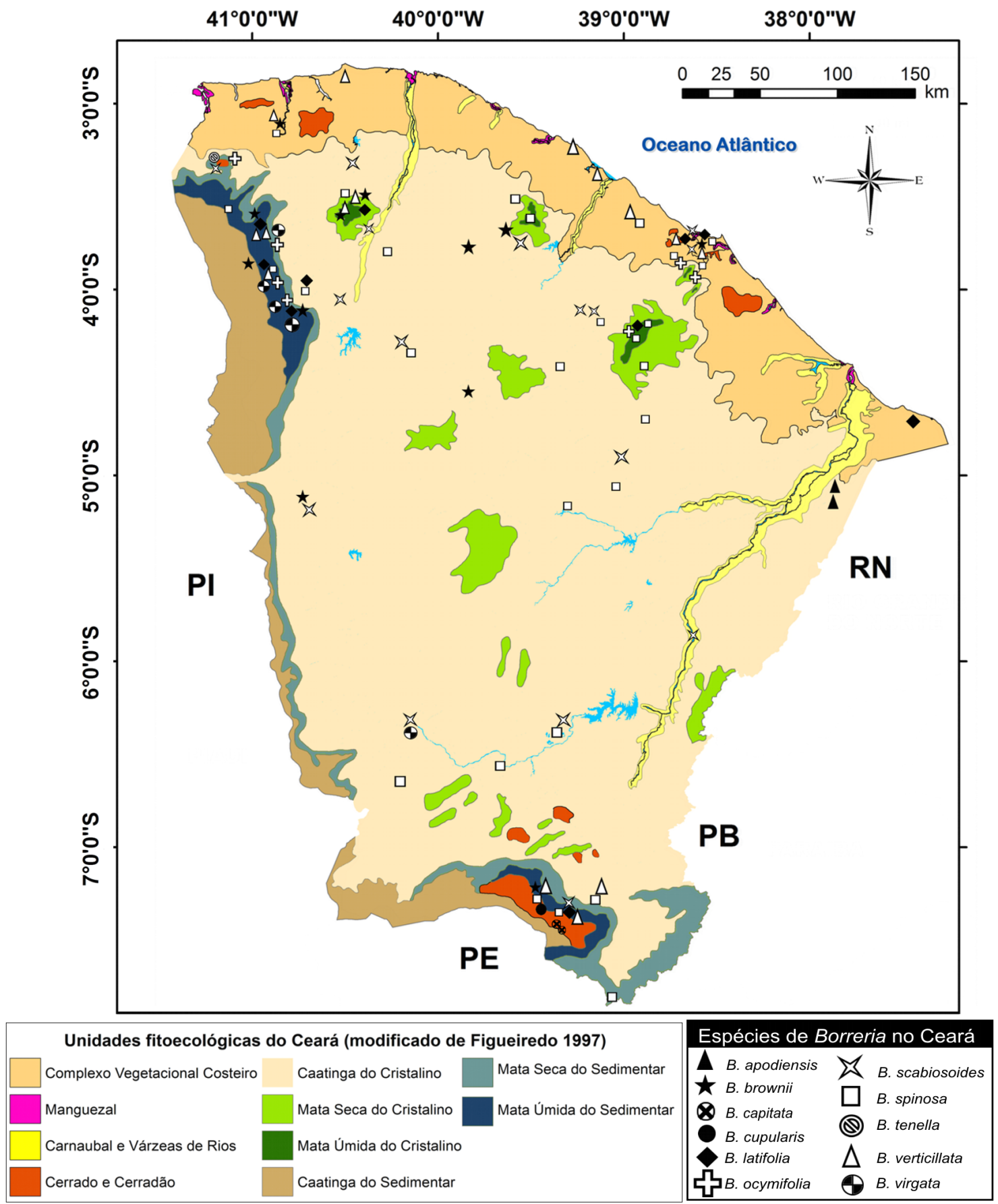

Figura 1 - Mapa de distribuição geográfica das espécies de Borreria no estado do Ceará, Nordeste do Brasil. Figure 1 - Map of geographical distribution of Borreria species in the Ceará state, Northeast Brazil.

ou estreito, com ou sem elaiossomos, estrofíolo ultrapassando ou não as margens da semente.

O gênero Borreria está representado no estado do Ceará por 11 espécies, cuja distribuição nas unidades fitoecológicas e domínios geológicos é apresentada na Tabela 1 e Figura 1. Entre as unidades fitoecológicas, a Caatinga é a mais representativa, com sete espécies, enquanto que a Floresta Subcaducifólia Tropical Xeromorfa (Cerradão) é a menos representativa, com duas 

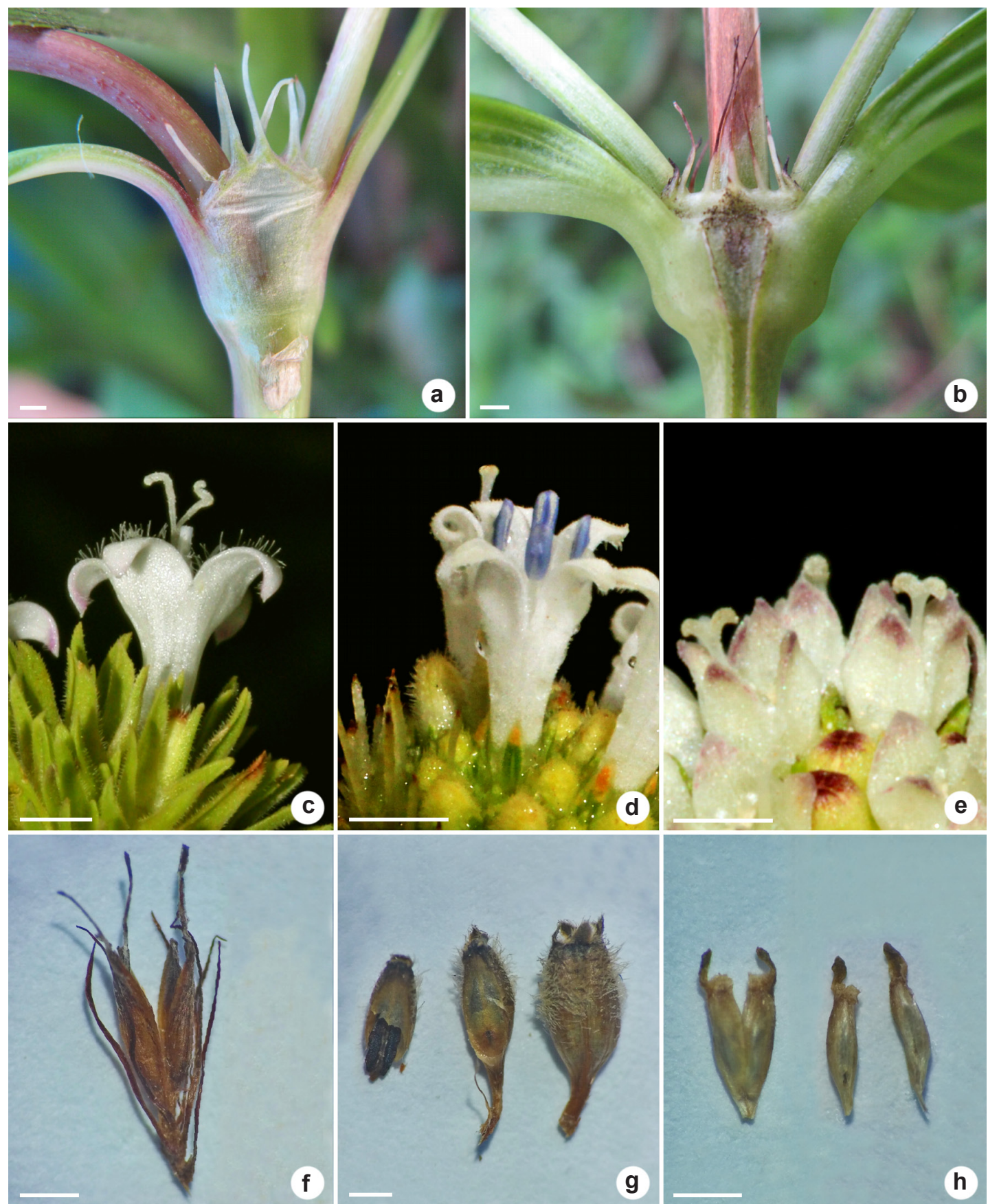

h

Figura 2 - Caracteres diagnósticos das espécies de Borreria para o Ceará. Bainha estipular. a. Borreria scabiosoides - bainha glabra. b. B. virgata - bainha pubescente. Forma da corola e estigma. c. B. latifolia - corola infundibuliforme e estigma largamente bífido. d. B. tenella -corola infundibuliforme e estigma bilobado. e. B. verticillata-corola campanulada e estigma curtamente bífido. Deiscência da cápsula. f. B. apodiensis - cápsula deiscente com ambas valvas deiscentes. g. B. ocymifolia cápsula deiscente com uma valva indeiscente e outra parcialmente deiscente. h. B. verticillata - cápsula deiscente com ambas as valvas indeiscentes. Escala: $1 \mathrm{~mm}$. Fotos: a,b. E. Souza; c,d. D. Cardoso; e. R. Salas.

Figure 2 - Diagnostics characters of Borreria species from Ceará. Stipular sheath. a. Borreria scabiosoides - glabrous sheath. b. B. virgata pubescent sheath. Shape of corolla and type of stigma. c. B. latifolia -infundibuliform corolla and long bifid stigma. d. B. tenella -infundibuliform corolla and bilobate stigma. e. B. verticillata - campanulate corolla and short bifid stigma. Dehiscence of the capsule. f. B. apodiensis - dehiscent capsule with both dehiscent valves. g. B. ocymifolia - dehiscent capsule with one indehiscent valve and another partially dehiscent valve. h. $B$. verticillata - dehiscent capsule with both indehiscent valves. Scale: 1 mm. Photos: a,b. E. Souza; c,d. D. Cardoso; e. R. Salas. 
Tabela 1 - Distribuição das espécies de Borreria por unidade fitoecológica e domínio geológico no estado do Ceará. $[\mathrm{CAA}=$ Caatinga $\mathrm{CRR}=$ Carrasco $; \mathrm{CER}=$ Cerrado $\mathrm{CED}=$ Floresta Subcaducifólia Tropical Xeromorfa (Cerradão); $\mathrm{CVL}=$ Complexo Vegetacional da Zona Litorânea; MTC $=$ Floresta Mista Dicótilo-Palmácea; MTS= Floresta Subcaducifólia Tropical Pluvial (Mata Seca); MTU= Floresta Subperenifólia Tropical Plúvio-Nebular (Mata Úmida)]; $[\mathrm{SED}=$ Sedimentar; CRIS $=$ Cristalino $]$.

\begin{tabular}{|c|c|c|c|c|c|c|c|c|c|c|}
\hline \multirow{2}{*}{ Espécie } & \multicolumn{8}{|c|}{ Unidades Fitoecológicas do Ceará } & \multicolumn{2}{|c|}{ Domínio Geológico } \\
\hline & CVL & MTU & MTS & CAA & CRR & MTC & CED & CER & SED & CRIS \\
\hline B. apodiensis & & & & $\mathrm{x}$ & & & & & $\mathrm{X}$ & \\
\hline B. brownii & $\mathrm{X}$ & $\mathrm{X}$ & $\mathrm{X}$ & $\mathrm{x}$ & $\mathrm{X}$ & $\mathrm{X}$ & & & $\mathrm{x}$ & $\mathrm{X}$ \\
\hline B. capitata & & & & & & & $\mathrm{X}$ & $\mathrm{X}$ & $\mathrm{X}$ & \\
\hline B. cupularis & & & & & & & $\mathrm{X}$ & $\mathrm{x}$ & $\mathrm{X}$ & \\
\hline B latifolia & $\mathrm{x}$ & $\mathrm{X}$ & $\mathrm{X}$ & $\mathrm{X}$ & & & & & $\mathrm{X}$ & $\mathrm{x}$ \\
\hline B. ocymifolia & & $\mathrm{X}$ & $\mathrm{X}$ & & & & & & $\mathrm{X}$ & \\
\hline B. scabiosoides & & & $\mathrm{X}$ & $\mathrm{x}$ & & $\mathrm{x}$ & & & $\mathrm{X}$ & $\mathrm{x}$ \\
\hline B. spinosa & $\mathrm{X}$ & $\mathrm{X}$ & $\mathrm{X}$ & $\mathrm{X}$ & $\mathrm{X}$ & $\mathrm{X}$ & & $\mathrm{X}$ & $\mathrm{x}$ & $\mathrm{x}$ \\
\hline B. tenella & & & & & & & & $\mathrm{X}$ & & $\mathrm{X}$ \\
\hline B. verticillata & $\mathrm{X}$ & $\mathrm{X}$ & $\mathrm{X}$ & $\mathrm{X}$ & $\mathrm{X}$ & $\mathrm{X}$ & & $\mathrm{X}$ & $\mathrm{X}$ & $\mathrm{X}$ \\
\hline$B$. virgata & & $\mathrm{X}$ & & $\mathrm{X}$ & & & & & $\mathrm{X}$ & \\
\hline
\end{tabular}

espécies catalogadas. Na Floresta Perenifólia Paludosa Marítima (Manguezal), não foi registrada nenhuma espécie de Borreria. Além disso, cinco das espécies ocorrem no domínio geológico sedimentar e uma sobre o cristalino. As demais cinco espécies ocorrem tanto no sedimentar quanto no cristalino. Dentre as espécies registradas neste estudo, nove ocorrem em Unidades de Conservação Ambiental: RPPN da Serra das Almas [B. brownii (Rusby) Standl.], Estação Ecológica de Aiuaba (B. scabiosoides Cham. \& Schltdl. e B. virgata Cham. \& Schltdl.), Estação Ecológica do Pecém (B. verticillata), Floresta Nacional do Araripe (B. spinosa), Parque Botânico do Ceará [B. latifolia (Aubl.) K. Schum., B. scabiosoides e B. verticillata] e Parque Nacional de Ubajara (B. ocymifolia, B. spinosa, $B$. verticillata e $B$. virgata).

\section{Chave de identificação das espécies de Borreria ocorrentes no estado do Ceará}

1. Folhas pseudoverticiladas, braquiblastos muito desenvolvidos.

2. Inflorescências em glomérulos unilaterais; flores pediceladas; cápsulas turbinadas e estipitadas 6. Borreria ocymifolia

2'. Inflorescências em glomérulos bilaterais; flores sésseis; cápsulas elipsoides, oblongoides ou obcônicas e sésseis.

3. Flores com cálice 2-mero, raro 3-mero, estigma curtamente bífido; cápsulas oblongoides.

4. Glomérulos globosos; flores com lobos do cálice linear-espatulados; cápsulas até 2,5 mm compr., glabras 10. Borreria verticillata

4'. Glomérulos hemisféricos; flores com lobos do cálice estreito-triangulares; cápsulas até $4 \mathrm{~mm}$ compr., pilosas no terço superior 8. Borreria spinosa

3'. Flores com cálice 4-mero, estigma bilobado; cápsulas elipsoides ou obcônicas.

5. Ramos glabros; flores com lobos do cálice estreito-triangulares; sementes com face dorsal fovéolo-reticulada e com elaiossomos no encaixe ventral

3. Borreria cupularis

5'. Ramos pubescentes; flores com lobos do cálice lineares ou estreito-triangulares; sementes com face dorsal transversalmente sulcada e sem elaiossomos no encaixe ventral. 
6. Folhas pseudopecioladas, face abaxial glabra ou pubescente sobre as nervuras, face adaxial glabra ou pilosa sobre as nervuras; flores com lobos do cálice lineares; cápsulas até $4 \mathrm{~mm}$ compr., obcônicas e pubescentes no terço superior 11. Borreria virgata

6'. Folhas sésseis, face abaxial hirsuta sobre as nervuras, face adaxial escabra; flores com lobos do cálice estreito-triangulares; cápsulas até $2,3 \mathrm{~mm}$ compr., elipsoides e glabras a escabras no terço superior

3. Borreria capitata

1'. Folhas opostas, braquiblastos ausentes ou pouco desenvolvidos.

7. Plantas paludosas, geralmente radicantes nos nós basais; sementes com estrofíolo ultrapassando a exotesta 7. Borreria scabiosoides

7'. Plantas não paludosas, não radicante nos nós basais; sementes com estrofíolo não ultrapassando a exotesta.

8. Ramos alados; inflorescências em glomérulos diminuindo de diâmetro em direção ao ápice

5. Borreria latifolia

8'. Ramos sem alas; inflorescências em glomérulos sempre com o mesmo diâmetro.

9. Lâminas foliares estreito-elípticas a lineares; flores com corola infundibuliforme

9. Borreria tenella

9'. Lâminas foliares elípticas; flores com corola ciatiforme.

10. Lâminas foliares plicadas; flores com lobos do cálice estreito-triangulares; sementes com face dorsal sem sulcos transversais 1. Borreria apodiensis

10'. Lâminas foliares não plicadas; flores com lobos do cálice ovados; sementes com face dorsal transversalmente sulcada 2. Borreria brownii

1. Borreria apodiensis E.L. Cabral, L.M. Miguel \& E.B. Souza, Act. Bot. Bras. 30: 2, 2016.

Figs. 2f; 3a

Erva ou subarbusto, ereto ou ascendente, (5-)20-50(-100) cm alt. Ramos quadrangulares a subquadrangulares, glabros a glabrescentes, verde-amarelados. Bainha estipular $3-5 \mathrm{~mm}$ de compr., pubérula, (6-)8-10(-14) setas, 1-3(-5) $\mathrm{mm}$ compr., glabras ou pubescente na base, filiformes, com coléter apical. Folhas opostas, raramente pseudoverticiladas, sésseis, raramente pseudopecioladas, lâmina $(3,5-) 5-7,5(-10) \times$ $0,5-2 \mathrm{~cm}$, elíptica, ápice agudo, base atenuada, membranácea a cartácea, face abaxial pilosa sobre as nervuras, glabrescente na face adaxial, margem revoluta, escabra, nervuras secundárias 5-6, alternas, plicadas. Inflorescências terminais e axilares, bilaterais, (1-)2-4(-5) glomérulos por ramo, (5-)10-20(-25) mm diâm., hemisféricos, subtendidos por 4-8(-12) brácteas foliáceas desiguais. Flores sésseis; cálice 4-mero, lobos 2-2,5 $\mathrm{mm}$ compr., estreito-triangulares, margem pilosa; corola 4-mera, 5-6,5 mm compr., ciatiforme, glabrescente no tubo e pilosa no ápice dos lobos, alva; estigma bilobado; disco bipartido. Cápsulas $(3,5-) 4-5 \times 1-1,5 \mathrm{~mm}$, elipsoides ou oblongoides, castanhas, pilosas no terço superior, deiscentes em 2 valvas unidas na base, cada valva deiscente. Sementes $2-2,5 \times 0,5-0,8 \mathrm{~mm}$, elipsoides, castanhas, face dorsal reticulada e encaixe ventral com sulco longitudinal.

Material examinado: Limoeiro do Norte, 28.V.2015, fl. e fr., E.B. Souza et al. 3549, 3555 (CTES, EAC, HUEFS, HUVA). Quixeré, 3.VII.1996, fl., L.W. Lima-Verde et al. 269 (CTES, EAC).

É semelhante à Borreria brownii, por possuir corola ciatiforme e frequentemente folhas opostas, contudo B. apodiensis possui folhas plicadas sobre as nervuras secundárias ( $v s$. folhas não plicadas), lobos do cálice estreito-triangular ( $v s$. lobos do cálice ovados) e face dorsal da semente sem sulcos transversais ( $v s$. face dorsal transversalmente sulcada). Espécie endêmica da Chapada do Apodi (Souza et al. 2016). Cresce em vegetação de Caatinga em solos sedimentares (Tab. 1, Fig. 1), sendo essencialmente uma espécie heliófita, sobre solos arenosos de rochas calcárias.

2. Borreria brownii (Rusby) Standl., Publ. Field Mus. Nat. Hist., Bot. Ser., 7: 333, 1931. Fig. 3b Subarbusto ereto, 20-70(-100) cm alt. Ramos cilíndricos a tetrágonos, glabros à glabrescentes, verde-amarelados. Bainha estipular (2-)4-6(-12) $\mathrm{mm}$ compr., glabrescente, 7-9 setas, (1-)3$9(-10) \mathrm{mm}$ compr., glabras a glabrescentes, filiformes, com coléter apical. Folhas opostas, pseudopecioladas, pseudopecíolo $1-2,5 \mathrm{~cm}$ compr., lâmina $(1,6-) 2-8(-16,5) \times 0,4-3(-5,5)$ $\mathrm{cm}$, elíptica, ápice agudo, base atenuada, margem 

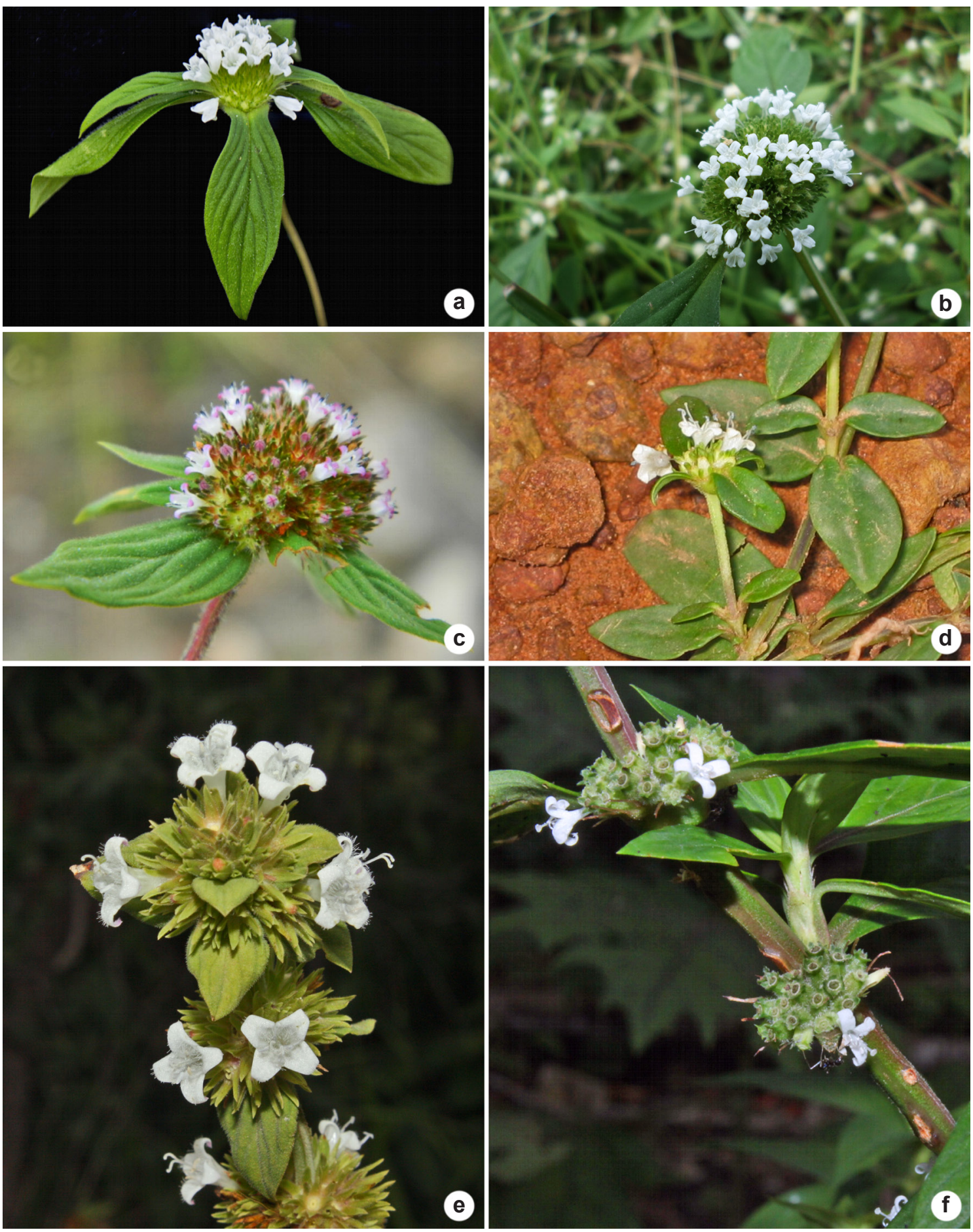

Figura 3 - Ramos com glomérulos terminais e/ou axilares. a. Borreria apodiensis - glomérulo terminal. b. B. brownii-detalhe do glomérulo terminal. c. B. capitata - glomérulo terminal. d. B. cupularis - glomérulo terminal. e. B. latifolia - glomérulos terminal e axilares. f. B. ocymifolia - glomérulos axilares. Fotos: a. E. Thomaz, b. A. Nepomuceno, c. S. Sobrado, d. E. Souza, e. D. Cardoso, f. R. Salas.

Figure 3 - Branches with terminal and/or axillary glomerules. a. Borreria apodiensis - terminal glomerule. b. B. brownii - details of terminal glomerule. c. B. capitata -terminal glomerule. d. B. cupularis-terminal glomerule. e. B. latifolia -terminal and axillary glomerules. f. B. ocymifolia -terminal and axillary glomerules. Photos: a. E. Thomaz, b. A. Nepomuceno, c. S. Sobrado, d. E. Souza, e. D. Cardoso, f. R. Salas. 
plana, membranácea a cartácea, escabra, face abaxial pubérula e adaxial pubérula a pubescente, nervuras secundárias 4-8(-10), alternas, impressas. Inflorescências terminais e axilares, bilaterais, 1-3 glomérulos por ramo, (6-)8-14(-30) mm diâm., hemisféricos, subtendidos por (2-)4-8 brácteas foliáceas. Flores sésseis; cálice 4-mero, lobos 0,8-1(-1,5) mm compr., ovados, margem ciliada; corola 4-mera, (3-)4,5-6 mm compr., ciatiforme, alva, glabra; estigma bilobado; disco bipartido. Cápsulas (3-)4-5 × 2-3 mm, elipsoides, castanhas, pilosas no terço superior, deiscentes em 2 valvas unidas na base, cada valva deiscente. Sementes 2-3 $\times 1-1,5 \mathrm{~mm}$, elipsoides, castanho-claras, face dorsal transversalmente sulcada e encaixe ventral longitudinalmente sulcado.

Material selecionado: Alcântaras, 23.III.2011, fl., E.B. Souza et al. 2073 (HUVA). Crateús, Serra das Almas, VII.2004, fl., K.M.E. Linhares 59 (EAC). Crato, 20.III.2000, fl., P. Delprete et al. 7271 (EAC, HUVA). Granja, 28.IV.2012, fl., E.B. Souza et al. 2550 (HUVA). Guaraciaba do Norte, Sítio Cachoeira do Urubu, 30.IV.2010, fl., E.K. Brandão et al. 19 (EAC, HUVA). Itapajé, Serra dos Coquinhos,18.V.2011, fl. e fr., D.A. Lima 123 (HUVA). Meruoca, Sítio Santa Cruz, 10.IV.2015, fl., E.B. Souza \& F.A.A. Nepomuceno 3308 (HUVA). Tianguá, Sítio do Bosco, 31.IV.2013, fl. e fr., E.B. Souza et al. 2827 (EAC, HUVA). Ubajara, 7.III.2003, fl., E.B. Souza et al. 731 (HUVA).

É similar à Borreria remota (Lam.) Bacigalupo \& E.L. Cabral por apresentar corola ciatiforme e sementes transversalmente sulcadas na face dorsal, sendo diferenciada pelo hábito geralmente ereto ( $v s$. hábito escandente) e glomérulos bilaterais (vs. glomérulos unilaterais). Também possui semelhança com B. apodiensis, sendo diferenciada nos comentários desta espécie. Ocorre do México até o noroeste da Argentina (Cabral et al. 2011). No Brasil, é registrada em vários estados da região Nordeste (MA, $\mathrm{CE}, \mathrm{RN}$, $\mathrm{PB}$ e BA) (BGF 2015). No Ceará, é encontrada em áreas de Restinga, Caatinga, Mata Seca e Mata Úmida, tanto em terrenos de origem sedimentar quanto cristalina (Tab. 1, Fig. 1). Cresce geralmente em locais sombreados, ao longo de cursos d'água sobre solos areno-argilosos como espécie ciófita ou raramente em locais abertos como espécie heliófita.

3. Borreria capitata (Ruiz \& Pav.) DC., Prodr. 4: 545. $1830 . \quad$ Fig. 3c

Erva a subarbusto ereto, $10-70 \mathrm{~cm}$ alt. Ramos cilíndricos a subtetrágonos, pubescentes, ferrugíneos; braquiblastos muito desenvolvidos. Bainha estipular 2-3 mm compr., pubescente a hirsuta, 7-10 setas, 2-5 mm compr., glabras, filiformes. Folhas pseudoverticiladas pela presença de braquiblastos, sésseis, lâmina (1,5-)2-5 × 0,3-0,8 cm, elíptica a estreito-elíptica, ápice agudo a acuminado, base atenuada, margem plana a levemente revoluta, cartácea, escabra, face abaxial hirsuta sobre as nervuras, face adaxial escabra, nervuras secundárias 5-6, alternas, plicadas. Inflorescências terminais e axilares, bilaterais, 1-3 glomérulos por ramo, $0,5-0,8 \mathrm{~cm}$ diâm., hemisféricos, subtendidos por 2-6 brácteas foliáceas. Flores sésseis; cálice 4-mero, lobos 1,5-2 $\mathrm{mm}$ compr., estreito-triangulares, margem pilosa; corola 4-mera, 2-4 mm compr., infundibuliforme, alva com ápice dos lobos lilases, glabra a micro-papilosa, estigma bilobado; disco bipartido. Cápsulas 1,5-2,3 × 0,5-1,2 mm, elipsoides, castanhas, glabras a escabras no terço superior, deiscentes em 2 valvas unidas na base, cada valva deiscente. Sementes $0,8-1,2 \times 0,5-0,1 \mathrm{~mm}$, elipsoides, castanhas, transversalmente sulcadas na face dorsal, encaixe ventral longitudinalmente sulcado.

Material examinado: Barbalha, Sítio Santa Rita, 30.III.2000, fl., P. Delprete et al. 7305 (EAC, HUVA).

É similar a Borreria tenella (Kunth) Cham. $\&$ Schltdl. quanto ao hábito e cor e forma do indumento nos ramos, sendo diferenciada por apresentar folhas pseudoverticiladas com braquiblastos muito desenvolvidos ( $v s$. folhas opostas com braquiblastos ausentes ou pouco desenvolvidos), face abaxial hirsuta sobre as nervuras e adaxial escabra ( $v s$. face abaxial e adaxial glabras), cápsulas elipsoides (vs. cápsulas obcônicas) e semente transversalmente sulcada na face dorsal (vs. semente fovéolo-reticulada na face dorsal). Também possui semelhança $\operatorname{com} B$. scabiosoides e $B$. virgata, sendo diferenciadas nos comentários destas espécies. Ocorre em quase todos os países da América do Sul, exceto Argentina, Chile e Uruguai (Cabral \& Bacigalupo 1999). No Brasil é registrada em praticamente todos os estados (exceto Acre e Mato Grosso do Sul) (BFG 2015). No Ceará, é encontrada em áreas de Cerrado e Cerradão (Tab. 1, Fig. 1), sobre solos arenosos e areno-argilosos. Cresce geralmente em áreas abertas e ensolaradas, ocorrendo como uma espécie heliófita.

4. Borreria cupularis DC., Prodr. 4: 543. 1830.

Fig. 3d

Erva ereta, $5-15 \mathrm{~cm}$ alt. Ramos subtetrágonos a tetrágonos, glabros, verde-amarelados a ferrugíneos. Bainha estipular 2-3 mm compr., 
pubescente, 5-9 setas, 2-4 mm compr., glabras, filiformes. Folhas pseudoverticiladas pela presença de braquiblastos, pseudopecioladas, pseudopecíolo $1-1,5 \mathrm{~cm}$ compr., lâmina $2,5-3,5 \times 0,4-0,7 \mathrm{~cm}$, estreito-elíptica, ápice agudo a acuminado, base atenuada, margem plana a levemente revoluta, cartácea, escabra, face abaxial glabra a pilosa sobre as nervuras e adaxial esparsamente pubérula, nervuras secundárias 5-6 alternas, impressas. Inflorescências terminais e axilares, bilaterais, 1(-3) glomérulos por ramo, 1-1,5 cm diâm., hemisféricos, subtendidos por 6-10 brácteas foliáceas. Flores sésseis; cálice 4-mero, lobos 1,5-2 $\mathrm{mm}$ compr., estreito-triangulares, margem ciliada; corola 4-mera, 1,5-3 mm compr., infundibuliforme, alva, papilosa; estigma bilobado; disco bipartido. Cápsulas 2,5-3,5 × 1-1,2 mm, elipsoides, castanhas, glabras a levemente pilosas no terço superior, deiscentes em 2 valvas unidas na base, cada valva deiscente. Sementes $1-1,5 \times 0,5-0,8$ $\mathrm{mm}$, oblongoides, castanhas, fovéolo-reticuladas na face dorsal, encaixe ventral longitudinalmente sulcado, coberto até a metade por elaiossomos.

Material examinado: Crato, estrada velha da Minguiriba, 22.V.2011, fl. e fr., E.B. Souza et al. 2104 (HUEFS, HUVA).

O hábito ereto, geralmente não ultrapassando $30 \mathrm{~cm}$, frequentemente com apenas um glomérulo terminal e sementes com encaixe ventral coberto até a metade por elaiossomos são caracteres diagnósticos da espécie. Ocorre no Peru, Bolívia, Brasil e Paraguai (Cabral et al. 2011). No Brasil, tem registro para as regiões Norte, Nordeste, Centro-Oeste e Sudeste (BFG 2015). Este é o segundo registro da espécie para a região Nordeste, sendo citada anteriormente apenas para o estado da Bahia. Espécie heliófita habitando solos arenoargilosos na Chapada do Araripe em vegetação de Cerrado e Cerradão (Tab. 1, Fig. 1).

\section{Borreria latifolia (Aubl.) K. Schum., Fl. bras.} 6(6): 61, $1888 . \quad$ Figs. 2c; 3e

Erva a subarbusto, ereto a decumbente, 20-80 cm alt. Ramos tetrágonos, pubescentes, alados, verde-amarelados. Bainha estipular 3-5 mm compr., pubescentes, (5-)7-9 setas, (2-)37(-8) mm compr., pubescentes, filiformes. Folhas opostas, pseudopecioladas, pseudopecíolo 1,5-2 cm compr., lâmina 2-9,5(-13) × $0,7-) 2-5,5 \mathrm{~cm}$, elíptica, ápice agudo, base atenuada a decorrente, margem levemente revoluta, membranácea a cartácea, escabra, face abaxial pubérula sobre as nervuras e adaxial escabra a estrigosa, nervuras secundárias 5-6, alternas, plicadas. Inflorescências terminais e axilares, bilaterais, 4-10 glomérulos por ramo, 0,5-1,5 cm diâm., hemisféricos, subtendidos por 2-4 brácteas foliáceas. Flores sésseis; cálice 4-mero, lobos 0,8-1,2 mm compr., triangulares a estreito-triangulares, margem pilosa a pubescente; corola 4-mera, 3-4 mm compr., infundibuliforme, alva a lilás-claro, diminutamente papilosa; estigma profundamente bífido com ramos estigmáticos enrolados sobre si mesmo; disco bipartido. Cápsulas 3-5 × $3 \mathrm{~mm}$, obovoides, castanhas, pilosas, deiscentes em 2 valvas unidas na base, cada valva deiscente. Sementes $2-3 \times 1-2 \mathrm{~mm}$, oblongoides a elipsoides, castanho-claras, face dorsal suavemente reticulada e encaixe ventral profundamente sulcado.

Material selecionado: Barbalha, Sítio Santa Rita, 30.III.2000, fl. e fr., P. Delprete et al. 7307 (EAC). Caucaia, Parque Botânico do Ceará, 22.V.1998, fl. e fr., E.B. Souza 241 (EAC). Guaraciaba do Norte, Sítio Santa Izabel, 22.III.2000, fl. e fr., P. Delprete et al. 7240 (EAC). Meruoca, Sítio Santa Cruz, 22.VII.2015, fl. e fr., E.B. Souza 3667 (EAC, HUVA). Pacujá, Bom Gosto, 16.III.2011, fl. e fr., E.B. Souza et al. 2067 (EAC, HUVA). Tianguá, Sítio do Bosco, 31.IV.2013, fl. e fr., E.B. Souza et al. 2828 (EAC, HUVA). Ubajara, Sítio São Luís, 10.V.2010, fl. e fr., E.M. Marreira et al. 94 (EAC, HUVA).

Apesar da grande variação morfológica no hábito, indumento e folhas, o caule alado e a coloração verde-amarelada ao secar são características diagnósticas para o reconhecimento de Borreria latifolia. Amplamente distribuída na América Central e do Sul (Cabral et al. 2011), a espécie ocorre em praticamente todos os estados do Brasil, exceto Rio Grande do Sul (BFG 2015). No Ceará apresenta-se como espécie ciófita ou raramente heliófita, sobre solos areno-argilosos na Floresta Subcaducifólia Tropical Pluvial e na Floresta Subperenifólia Tropical Plúvio-Nebular (Tab. 1, Fig. 1).

6. Borreria ocymifolia (Willd. ex Roem. \& Schult.) Bacigalupo \& E.L. Cabral, Opera Bot. Belg., 7: 307, 1996.

Figs. $2 \mathrm{~g} ; 3 \mathrm{f}$

Subarbusto ereto ou ascendente, 30-50(90) $\mathrm{cm}$ alt. Ramos tetrágonos, pubérulos a pubescente, verdes. Bainha estipular (2-)3-6 mm compr., pubérula, 7-10 setas, $1-5 \mathrm{~mm}$ compr., pubérulas, filiformes, com coléter apical. Folhas pseudoverticiladas pela presença de braquiblastos nas axilas, pseudopecioladas, pseudopecíolo $1-1,5$ cm compr., lâmina (1-)2-8(-9) × $(0,3-) 0,8-2(-2,2)$ $\mathrm{cm}$, elíptica a estreito-elíptica, ápice agudo, 
base atenuada a decorrente, margem revoluta, cartácea, escabra, face abaxial e adaxial escabra, nervuras secundárias 4-7 pares, levemente plicadas. Inflorescências axilares, unilaterais, 5-22 glomérulos por ramo, 5-11 cm diâm., hemisféricos, subtendidos por 2 brácteas foliáceas. Flores pediceladas, pedicelo $2 \mathrm{~mm}$ compr.; cálice 4-mero, lobos 0,3-0,5(-1) mm compr., triangulares, margem pilosa; corola 4-mera, 4-5 mm compr., subhipocrateriforme, alva, glabra; estigma capitado; disco inteiro. Cápsulas 3-5 $\times$ 1-2 mm, turbinadas, estipitadas, castanhas, densopubescentes, deiscentes em 2 valvas unidas na base, uma valva deiscente e outra parcialmente deiscente na base. Sementes $(2,2-) 3-3,5 \times 0,8-1 \mathrm{~mm}$, elipsoides, castanhas, face dorsal foveolada com leves estrias transversais, encaixe ventral estreito. Material selecionado: Graça, 27.VIII.2009, fl. e fr., E.B. Souza et al. 1759 (CTES, EAC, HUVA). Granja, Serra de Ubatuba, 26.IV.2012, fl. e fr., E.B. Souza et al. 2488 (EAC, HUVA). Ibiapina, Sítio Quatis, 20.XII.2013, fl. e fr., E.B. Souza et al. 2870 (EAC, HUVA). Maranguape, 7.XI.1998, fl. e fr., P. Delprete et al. 6896 (CTES, EAC, HUVA). Pacatuba, Serra da Aratanha, 26.III.2000, fl. e fr., P. Delprete et al. 7264 (HUVA). Ubajara, Parque Nacional de Ubajara, 3.VIII.2011, fl. e fr., E.B. Souza et al. 2237 (EAC, HUVA).

É bastante similar a Borreria remota quanto ao hábito e disposição e forma dos glomérulos, sendo diferenciada por possuir corola subhipocrateriforme (vs. corola ciatiforme) e semente com leves estrias transversais na face dorsal ( $v s$. semente com sulcos transversais na face dorsal). Ocorre na América Central, Caribe e América do Sul (Cabral et al. 2011). No Brasil, é registrada em todas as regiões (BFG 2015). Espécie ciófita, ocupando sub-bosque e margem de trilhas, sobre solos areno-argiloso na Floresta Subcaducifólia Tropical Pluvial e na Floresta Subperenifólia Tropical Plúvio-Nebular (Tab. 1, Fig. 1).

\section{Borreria scabiosoides Cham. \& Schultdl.,} Linnaea, 3: 318, 1828. Figs. 2a; $4 \mathrm{a}$

Erva paludosa, decumbente, $30-80(-100) \mathrm{cm}$ alt., radicante nos nós basais. Ramos cilíndricos, glabros, verde-vináceos a verde-amarelado no campo, plantas verde nigrescente quando secas. Bainha estipular (2-)4-6(-10) mm compr., glabra a pubescente, (3-)5-10 setas, (1-)2-8(-10) mm, glabras, filiformes, com coléter apical. Folhas opostas, sésseis, lâmina (2,2-)3,5-12,5 × 0,5-3,2 $\mathrm{cm}$, elíptica a estreito-elíptica, ápice agudo, base atenuada, margem plana ou levemente revoluta, cartácea, escabra, face adaxial e abaxial glabras a glabrescentes ou levemente escabras na face adaxial, nervuras secundárias 5-8, alternas, impressas. Inflorescências terminais, bilaterais, $1(-2)$ glomérulos por ramo, $0,5-3(-3,5) \mathrm{cm}$ diâm., hemisféricos, subtendidos por 2-4 brácteas foliáceas, basalmente denso-pubescentes. Flores sésseis; cálice 4-mero, lobos 1-2,5(-3) mm compr., lineares, pilosos na margem; corola 4-mera, (2-)3-5 mm compr., infundibuliforme, alva, micro-papilosa; estigma bilobado; disco bipartido. Cápsulas 2-5 × 0,8-2 mm, elipsoides, castanhas, pilosas no terço superior, deiscentes em 2 valvas unidas na base, cada valva deiscente. Sementes 1,5-3 × 0,5-1 mm, elipsoides, castanhas, face dorsal fovéolo-reticulada e encaixe ventral com sulco longitudinal e estrofíolo ultrapassando a margem da exotesta.

Material selecionado: Barbalha, Chapada do Araripe,23.V.2011, fl. e fr, E.M. Marreira et al. 169 (HUVA). Caridade, Lagoa Contendas, 6.VI.2009, fl. e fr., A.B. Tabosa 11 (EAC). Caucaia, Parque Botânico do Ceará, 17.IV.1998, fl., L.Q. Matias 165 (EAC). Crateús, 21.V.1997, fl., E.O. Barros \& L.W. Lima-Verde 20 (EAC). Granja, Serra de Ubatuba, 28.IV.2012, fl., E.B. Souza et al. 2535 (HUVA). Iguatu, 15.V.2010, fl., L.R.O. Normando et al. 214 (HUVA). Irauçuba, Fazenda Mimoso, 23.III.2000, fl., E.B. Souza et al. 7244 (EAC, HUVA). Itapajé, Serra de Uruburetama, 18.V.2011, fl., D.A. Lima 121 (HUVA). Jaguaribe, 12.IV.2011, fl., A.M. Miranda et al. 6316 (EAC). Senador Sá, 13.IV.2014, fl., E.B. Souza et al. 3118 (EAC, HUVA). Sobral, Fazenda Experimental da UVA, 9.IV.2015, E.B. Souza et al. 3277 (HUVA).

Possui similaridade quanto à forma e tamanho do glomérulo com Borreria capitata, sendo distinta desta por ser glabra ( $v s$. pubescente), paludosa (vs. não paludosa) e apresentar hábito decumbente ( $v s$. hábito frequentemente ereto). Também é similar a B. virgata quanto ao hábito, sendo diferenciada por apresentar folhas não plicadas ( $v s$. folhas plicadas) e sementes com face dorsal fovéolo-reticulada ( $v s$. sementes com face dorsal transversalmente sulcada). É amplamente distribuída na América Central e do Sul (Cabral et al. 2011). Ocorre em praticamente todos os estados do Brasil, exceto na região Sul (BFG 2015). No Ceará, habita especialmente a Caatinga (Tab. 1, Fig. 1), geralmente na margem de matas, estradas e como invasora de cultivos, sendo uma espécie heliófita e seletiva higrófila, sobre solos arenoargilosos ou raramente sobre solos arenosos. No entanto também possui registros para áreas de Floresta Subcaducifólia Tropical Pluvial e Floresta Mista Dicótilo-Palmácea (Tab. 1., Fig. 1). 

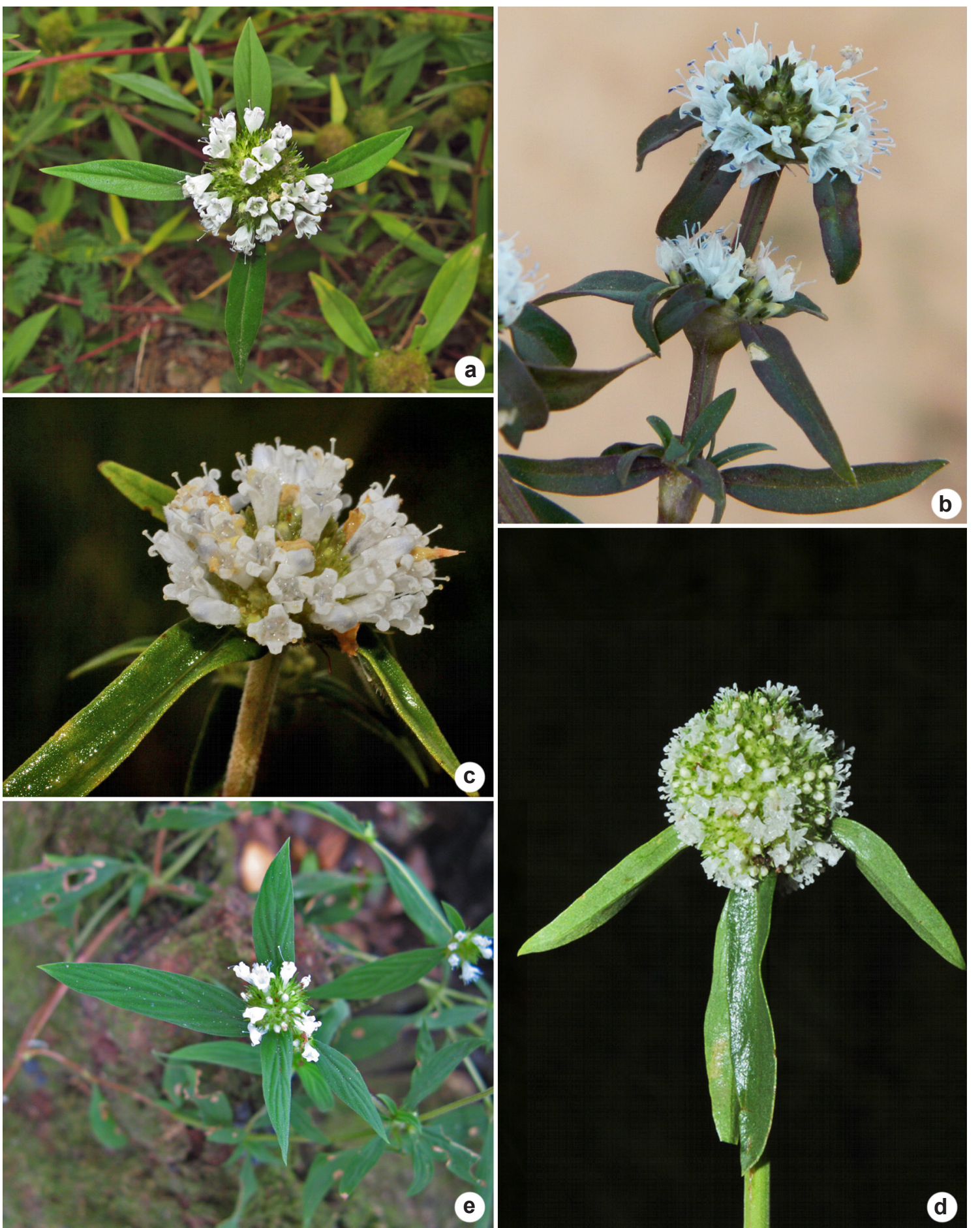

Figura 4 - Ramos com glomérulos terminais e/ou axilares. a. Borreria scabiosoides - glomérulo terminal. b. $B$. spinosa - glomérulo terminal e axilar. c. B. tenella - glomérulo terminal. d. B. verticillata - glomérulo terminal. e. B. virgata-glomérulo terminal. Fotos: a,e. E. Souza, b. S. Sobrado, c,d. R. Salas.

Figure 4 - Branches with terminal and/or axillary glomerules. a. Borreria scabiosoides - terminal glomerule. b. B. spinosa - terminal and axillary glomerule. c. B. tenella - terminal glomerule. d. B. verticillata - terminal glomerule. e. B. virgata - terminal glomerule. Photos: a,e. E. Souza, b. S. Sobrado, c,d. R. Salas. 
8. Borreria spinosa Cham. \& Schltdl. ex. DC., Prod. 4: 542. 1830.

Fig. $4 \mathrm{~b}$

Erva ou subarbusto, ereto ou ascendente, 10-100 cm alt. Ramos tetrágonos, glabros ou pubescentes, às vezes com papilas de base grossa nas margens, verde-claros; braquiblastos muito desenvolvidos. Bainha estipular (2-)4-5 mm compr., glabrescente, 5-11 setas, (1-)2-7 mm compr., glabrescentes, filiformes, com coléter apical. Folhas pseudoverticiladas pela presença de braquiblastos, sésseis a pseudopecioladas, pseudopecíolo 1-2 cm compr., lâmina (2-)2,5$7,5(-8) \times(0,5-) 1-2,5 \mathrm{~cm}$, elíptica a estreitoelíptica, ápice agudo, base atenuada, margem plana, cartáceas, escabra, face abaxial e adaxial glabrescente, às vezes com papilas de base grossa na face abaxial, nervuras secundárias 3-7, alternas, impressas. Inflorescências terminais e axilares, bilaterais, (1-)2-5 glomérulos por ramo, (0,6-)1-2 cm diâm., hemisféricos, subtendidos por 4-6(-8) brácteas foliáceas. Flores sésseis; cálice 2-mero, raro 3-mero, lobos 1,5-2,5 mm compr., linear-triangulares, pilosos na margem; corola 4-mera, 2-4 mm compr., campanulada, alva, glabra; estigma curtamente bífido; disco bipartido. Cápsulas 2-4 × 0,8-1,2 $(-1,5) \mathrm{mm}$, oblongoides, castanhas, pilosas no terço superior, deiscentes em 2 valvas unidas na base, cada valva deiscente. Sementes $1-1,5 \times 0,2-0,3 \mathrm{~mm}$, oblongoides a subcilíndricas, castanhas, fovéolo-reticuladas na face dorsal e encaixe ventral longitudinalmente sulcado.

Material selecionado: Aiuaba, Gameleira de Cima, 9.IV.1997, fl., L.W. Lima-Vede 565 (EAC). Alcântaras, Sítio Bonfim, 15.III.2000, fl. e fr., P. Delprete et al. 7179 (EAC, HUVA). Canindé, BR-020, 11.IV.1998, fl. e fr., E.B. Souza 195 (EAC). Capistrano, Fazenda Araçanga, 30.V.1994, fl. e fr., J.B.L.P. Medeiros \& L.W. LimaVerde 80 (EAC). Caucaia, Sargento-Mor, 6.VIII.2011, f1., A.S.F. Castro \& P. Delprete 2538 (EAC). Crato, Floresta Nacional do Araripe, 7.VI.2000, fl. e fr., L.W. Lima-Verde 2143 (EAC). Fortaleza, Fazenda Natália, 30.V.2008, fl., M.F. Moro et al. 403 (HUVA). Granja, Serra de Ubatuba, 26.IV.2012, fl., E.B. Souza et al. 2487 (EAC, HUVA). Guaramiranga, Sítio Limoeiro, 11.XI.1998, fl. e fr., P. Delprete et al. 6904 (EAC, HUVA). Ibiapina, Sítio Boa Água, 27.XII.2013, fl., E.B. Souza et al. 2932 (EAC, HUVA). Iguatu, 16.V.2010, fr., L.R.O. Normando et al. 244 (EAC, HUVA). Itapajé, Maciço de Uruburetama, 18.V.2011, fr., D.A. Lima 125 (HUVA). Itapipoca, Serra da Itacoatiara, 13.XI.2014, fl. e fr., F.D.S. Santos \& F.A.A. Nepomuceno 195 (HUVA). Jucás, Oitis, 5.IV.2000, fl., P. Delprete et al. 7321 (EAC; HUVA). Maranguape, 7.XI.1998, f1., $P$. Delprete et al. 6891 (EAC, HUVA). Meruoca, Serra da
Meruoca, 7.IV.2013, f1., J.E.M. Nascimento 90 (HUVA). Missão Velha, Parque Arajá, 18.VIII.2011, fl. e fr., E. Melo et al. 10275 (HUEFS, HUVA). Pacoti, Sítio São Luís, 19.XI.1998, fl., P. Delprete et al. 6910 (EAC). Pacujá, Serrinha, Bom Gosto, 26.VIII.2009, fl., E.B. Souza et al. 1746 (EAC, HUVA). Penaforte, 15.II.2011, fl., A.L. Alves \& W.A. Pimenta 17 (HUVA). Quixadá, Fazenda Olho D'Água, 14.VI.1993, fr., I.M. Andrade 33 (EAC). Santa Quitéria, 22.IV.2012, fl., J. PaulaSouza et al. 10946 (EAC). São Benedito, Sítio Penha, 5.XII.2008, fl., E.M. Marreira et al. 3 (HUVA). Sobral, Fazenda Experimental da UVA, 13.III.2015, f1., F.A.A. Nepomuceno \& F.D.S. Santos 79 (HUVA). Viçosa do Ceará, Sítio Laranjeiras, 12.IX.2014, fr., E.B. Souza et al. 3193 (HUVA). Ubajara, Parque Nacional de Ubajara, 3.VIII.2011, fl., E.K.S. Brandão et al. 53 (EAC, HUVA).

É similar a Borreria verticillata por possuir folhas pseudoverticiladas, às vezes com papilas de base grossa sobre a nervura principal na face abaxial e nervuras secundárias inconspícuas na face adaxial. Entretanto, distingue-se pelos glomérulos hemisféricos ( $v s$. glomérulos globosos) e flores com lobos do cálice linear-triangulares ( $v s$. flores com lobos do cálice linear-espatulados). Espécie com ampla distribuição nas Américas, desde o México até o centro da Argentina, geralmente tratada como ruderal e invasora de culturas (Cabral et al. 2011). No Brasil, ocorre em todas as regiões, porém na região Norte está registrada apenas para o estado de Tocantins (BFG 2015). Apresentase amplamente dispersa no Ceará, ocorrendo em todas as unidades fitoecológicas, exceto os manguezais (Tab. 1, Fig.1), como planta heliófita, raramente ciófita, sobre solos areno-argilosos ou arenosos.

9. Borreria tenella (Kunth) Cham. \& Schultdl., Linnaea, 3: 317, $1828 . \quad$ Figs. 2d; 4c Erva a subarbusto ereto, $30-80 \mathrm{~cm}$ alt. Ramos cilíndricos a subtetrágonos, glabrescentes a pubérulos, ferrugíneos. Bainha estipular 2-3,5 mm compr., glabras, (3-)4-9 setas, 2-6 mm compr., glabras, filiformes, com coléter apical. Folhas oposta, as vezes com braquiblastos pouco desenvolvidos, sésseis a curtamente pseudopecíoladas, pseudopecíolo $0,5-1 \mathrm{~cm}$ compr., lâmina 1,5-4,2 ×0,3-0,9(-1) cm, estreito-elíptica a linear, ápice acuminado, base atenuada, margem revoluta, cartácea, levemente escabra, face abaxial e adaxial glabras, nervuras secundárias 2-6, alternas, levemente plicadas. Inflorescências terminais e subterminais, bilaterais, 1-3 glomérulos por ramo, 0,6-1 cm diâm., hemisféricos, subtendidos por $2-8$ brácteas foliáceas. Flores sésseis; cálice 
4-mero, lobos 1,5-2 mm, lineares, piloso na margem; corola 4-mera, 2,5-3(-4) mm compr., infundibuliforme, alva, micro-papilosa; estigma bilobado; disco bipartido. Cápsulas 2-3 × 1-1,5 $\mathrm{mm}$, obcônicas, castanhas, glabras a pilosas no terço superior, deiscentes em 2 valvas unidas na base, cada valva deiscente. Sementes 1-1,5 $\times$ 0,4-0,5 mm, oblongoides, castanhas, fovéoloreticuladas na face dorsal, encaixe ventral longitudinalmente sulcado.

Material selecionado: Barroquinha, 10.VI.2016, fl. e fr., E.B. Souza et al. 4209 (HUVA). Granja, Serra de Ubatuba, 26.IV.2012, fl., E.B. Souza et al. 2504 (EAC, HUVA).

Ramos ferrugíneos, folhas opostas com braquiblastos pouco desenvolvidos e flores com os lobos do cálice lineares são características diagnósticas desta espécie. Ocorre da América Central até o norte da Argentina (Cabral et al. 2011). No Brasil, está relacionada ao bioma Cerrado, mas ocorre em todas as regiões (BFG 2015). No Ceará é encontrada como espécie heliófita, habitando restritamente o domínio geológico de origem sedimentar, em afloramentos rochosos e campos de altitudes com solos arenosos em vegetação de Cerrado (Tab. 1, Fig. 1).

10. Borreria verticillata (L.) G. Mey., Prim. Fl. Esseq. 83, 1818.

Figs. 2e,h; 4d

Subarbusto ascendente, $30-80(-100) \mathrm{cm}$ alt. Ramos cilíndricos, glabros, ferrugíneos. Bainha estipular 2-4 mm compr., glabra, 3-5 setas, (1-)2-7 mm compr., glabras, filiformes. Folhas pseudoverticiladas pela presença de braquiblastos muito desenvolvidos, sésseis a pseudopecíoladas, pseudopecíolo 1-1,5 cm compr., lâmina (1)2,5-5 × 0,3-1 cm, elíptica a estreito-elíptica, ápice agudo, base atenuada, margem plana, cartácea, levemente escabra, face abaxial e adaxial glabras, às vezes com papilas de base grossa sobre a nervura principal na face abaxial, nervuras secundárias (2-)3-6, alternas, impressas. Inflorescências terminais e axilares, bilaterais, 1-3 glomérulos por ramo, $0,5-1 \mathrm{~cm}$ diâm., globosos, subtendidos por 2-4 brácteas foliáceas. Flores sésseis; cálice 2-mero, lobos $0,5-1,5 \mathrm{~mm}$ compr., linear-espatulados, pilosos na margem; corola 4-mera, 1,5-2,8 mm compr., campanulada, alva, glabrescente; estigma curtamente bífido; disco bipartido. Cápsulas 1,5-2,3(-2,5) × 0,8-1 mm, oblongoides, castanhas, glabras, deiscentes em 2 valvas unidas na base, cada valva indeiscente com uma linha média longitudinal de deiscência pré-formada. Sementes $1-1,5 \times 0,3-0,5 \mathrm{~mm}$, elipsoides ou oblongoides, nigrescentes, face dorsal fovéolo-reticulada e encaixe ventral com sulco longitudinal.

Material selecionado: Alcântaras, Sítio Bonfim, 15.III.2000, fl. e fr., P. Delprete et al. 7180 (EAC, HUVA). Barbalha, Sítio Santa Rita, 30.III.2000, fl., P. Delprete et al. 7312 (EAC). Caucaia, Parque Botânico do Ceará, 8.V.1998, fr., E. Trigueiro 4 (EAC). Crato, Subida do Belmonte, 28.III.2000, fl. e fr., P. Delprete et al. 7295 (EAC, HUVA). Fortaleza, UFC, Campus do Pici, 16.XI.1998, fr., P. Delprete et al. 6920 (EAC, HUVA). Granja, Serra de Ubatuba, 26.IV.2012, fl. e fr., E.K.S. Brandão et al. 68 (EAC). Ibiapina, 20.XII.2013, fl. e fr., E.B. Souza et al. 2862 (EAC, HUVA). Jijoca de Jericoacoara, Lagoa do Meio, 4.V.2000, fl. e fr., L.Q. Matias 252 (EAC). Meruoca, 21.X.1998, fl. e fr, P. Delprete et al. 6856 (EAC, HUVA). Missão Velha, 19.VIII.2011, fl. e fr., E. Melo et al. 10427 (HUEFS, HUVA). São Gonçalo do Amarante, Estação Ecológica do Pecém, 27.VIII.2005, fl. e fr., I.J. Roberto 3 (EAC). Tianguá, Sítio Santa Rita, 23.VIII.2004. fr., L.W. LimaVerde 3013 (EAC). Trairi, Flexeiras, 19.IV.1999, fl. e fr., R. Amaro 119 (EAC). Viçosa do Ceará, Sítio Laranjeiras, 12.IX.2014, fl., E.B. Souza et al. 3192 (HUVA).

É similar a Borreria spinosa, da qual pode ser diferenciada pelas características indicadas nos comentários desta espécie. Distribui-se desde os Estados Unidos até o centro da Argentina (Cabral et al. 2011). No Brasil ocorre em todos os estados (BFG 2015). No Ceará, habita praticamente todas as unidades fitoecológicas (Tab. 1, Fig. 1) como espécie ciófita ou raramente heliófita, podendo ainda ocorrer em áreas parcialmente alagadas como uma espécie seletiva higrófita, sobre solos areno-argilosos ou raramente sobre solos arenosos. Também ocorre como planta ruderal em áreas degradadas, margens de estradas ou invasoras de pastagens naturais (Quadros et al. 2003).

11. Borreria virgata Cham. \& Schltdl., Linnaea 3: 324, 1828.

Figs. 2b; 4e

Subarbusto ascendente, $30-70(-120) \mathrm{cm}$ alt. Ramos tetrágonos a subtetrágonos, glabros a pubescentes nas margens, esfoliantes, ferrugíneos. Bainha estipular 2-5 $\mathrm{mm}$, pubescente, 5-9 setas, 2-5(-6) mm, glabras, filiformes. Folhas pseudoverticiladas pela presença de braquiblastos, pseudopecíoladas, pseudopecíolo $1-1,5 \mathrm{~cm}$ compr., lâmina $(1,5-) 2-5,5 \times 0,5-1(-2) \mathrm{cm}$, elíptica a estreito-elíptica, ápice agudo, base atenuada, margem levemente revoluta, cartácea, glabra ou pilosa, face abaxial e adaxial glabras 
ou pubescente na face abaxial e pilosa na face adaxial, nervuras secundárias 4-5, alternas, plicadas. Inflorescências terminais, bilaterais, 1-3 glomérulos por ramo, subglobosos, 0,6-1,5 mm diâm., subtendidos por 2-4 brácteas foliáceas. Flores sésseis; cálice 4-mero, lobos 1,5-2,5(-3) $\mathrm{mm}$, lineares, ciliados na margem; corola 4-mera, 3,5-5 mm compr., infundibuliforme, alva, papilosa; estigma bilobado; disco bipartido. Cápsulas 2-4 $\times$ 0,8-1 mm, obcônicas, castanhas, levemente pubescentes no terço superior; deiscente em 2 valvas unidas na base, cada valva deiscente. Sementes 1-1,5 × 0,5 mm, oblongoides, castanhas, face dorsal transversalmente sulcada e encaixe ventral com sulco longitudinal.

Material selecionado: Aiuaba, Estação Ecológica de Aiuaba, 30.VI.2004, fr., J.R. Lemos \& P. Matias 230 (EAC). Guaraciaba do Norte, 29.X.2009, fl. e fr., E.M. Marreira et al. 63 (EAC, HUVA). Ibiapina, Sítio Quatis, 20.XII.2013, fl. e fr., E.B. Souza et al. 2866, 2869 (HUVA, EAC). São Benedito, Sítio Penha, 29.X.2009, fl., E.M. Marreira et al. 59 (EAC, HUVA). Ubajara, Parque Nacional de Ubajara, 20.XII.2011, fl. e fr., E.M. Marreira et al. 234 (EAC, HUVA).

É muito confundida com Borreria capitata quanto à coloração dos ramos, forma dos glomérulos e ornamentação das sementes, mas se distingue por apresentar folhas pseudopecioladas (vs. folhas sésseis), face abaxial glabra ou pubescente sobre as nervuras ( $v s$. face abaxial hirsuta sobre as nervuras), face adaxial glabra ou pilosa sobre as nervuras (vs. face adaxial escabra), cápsulas até $4 \mathrm{~mm}$ compr., obcônicas e pubescentes no terço superior ( $v s$. cápsulas até 2,3 mm compr., elipsoides e glabras a escabras no terço superior). Também possui similaridade com B. scabiosoides, sendo diferenciada nos comentários desta espécie. Espécie com distribuição restrita à América do Sul, nas Guianas Francesa e Inglesa, Suriname e no Brasil, onde possui registro nos estados do Ceará, Bahia e Rio de Janeiro (BFG 2015; Cabral et al. 2011). No Ceará, habita áreas de Floresta Subperenifólia Tropical Plúvio-Nebular e Caatinga do Sedimentar com altitudes acima de $400 \mathrm{~m}$ (Tab. 1, Fig. 1), ao longo de cursos d'água no Planalto da Ibiapaba, entre afloramentos rochosos, como planta ciófita e seletiva higrófila, sobre solos areno-argilosos.

\section{Considerações Finais}

Entre as espécies de Borreria do Ceará, constatou-se uma maior representatividade de subarbustos (4 spp.; 36,36\%). As ervas foram representadas por três espécies $(27,27 \%)$ e as demais podem ocorrer como ervas ou subarbustos. Sete espécies são heliófitas $(72,72 \%)$, três são ciófitas $(27,27 \%)$ e três são seletivas higrófilas: $B$. scabiosoides, $B$. verticillata e $B$. virgata.

A maioria das espécies habita a vegetação de Caatinga e nove estão em Unidades de Conservação Ambiental. Apenas Borreria apodiensis, recentemente descrita por Souza et al. (2016), é endêmica do Brasil e restrita à Chapada do Apodi, nos limites entre os estados do Ceará e Rio Grande do Norte. Borreria brownii, B. spinosa e $B$. verticillata são amplamente distribuídas nas unidades fitoecológicas do Ceará (Tab. 1, Fig. 1). Quatro espécies apresentam ocorrência mais restrita: B. capitata e B. cupularis (na Chapada do Araripe, em vegetação de Cerrado e Cerradão, sobre o domínio geológico do Sedimentar), $B$. tenella (na Serra de Ubatuba e áreas adjacentes, em vegetação de Cerrado, sob influência do domínio geológico do Cristalino) e B. virgata (no Planalto da Ibiapaba, em vegetação de Mata Úmida, sobre o domínio geológico do Sedimentar).

\section{Agradecimentos}

Os autores agradecem à Universidade Estadual Vale do Acaraú e à equipe do herbário HUVA, a infraestrutura oferecida para a realização deste trabalho; à Fundação Cearense de Apoio ao Desenvolvimento Científico e Tecnológico FUNCAP, o apoio ao projeto "Inventário Florístico do Noroeste do estado do Ceará: Diversidade e Potencialidades do Bioma Caatinga" - Processo: BP2-0107-0081.01.02/16. Ao Conselho Nacional de Desenvolvimento Científico e Tecnológico - CNPq, a bolsa PIBIC - Iniciação Científica concedida ao primeiro autor durante sua graduação. A Domingos Cardoso, Roberto Salas e Sandra Sobrado, as fotografias cedidas.

\section{Referências}

Bacigalupo NM \& Cabral EL (1996) Infrageneric classification of Borreria (Rubiaceae Spermacoceae) on the basis of American species. Opera Botanica Belgica 7: 297-303.

Bacigalupo NM \& Cabral EL (1999) Revisión de las especies americanas del género Diodia (Rubiaceae, Spermacoceae). Darwiniana 37: 153-165.

Bacigalupo NM, Cabral EL \& Cabaña Fader AA (2010) Spermacoce spiralis, a new name for Diodia assurgens (Rubiaceae). Plant Ecology and Evolution 143: 100-104.

BFG - The Brazil Flora Group (2015) Growing knowledge: an overview of seed plant diversity in Brazil. Rodriguésia 66: 1085-1113. 
Burger W \& Taylor CM (1993) Rubiaceae. In: Burger W (ed.) Flora costaricensis. Fieldiana, Botany, new series 33: 1-333.

Cabral EL \& Bacigalupo NM (1996) Revision of Borreria section Pseudodiodia (Rubiaceae - Spermacoceae). Opera Botanica Belgica 7: 309-327.

Cabral EL \& Bacigalupo NM (1999) Estudio de las especies americanas de Borreria Series Laeves (Rubiaceae - Spermacoceae). Darwiniana 37: 259-277.

Cabral EL, Mari E \& Pire SM (2006) Borreria sect. Pseudodiodia (Rubiaceae), aportes taxonómicos y palinológicos. Bonplandia 15: 79-80.

Cabral EL, Cabanã-Fader AA \& Bacigalupo NM (2010) A new species of Spermacoce s. str. (Spermacoceae, Rubiaceae) from Eastern Brazil. Plant Ecology and Evolution 143: 233-238.

Cabral EL, Miguel LM \& Salas RM (2011) Dos especies nuevas de Borreria (Rubiaceae), sinopsis y clave de las especies para Bahia, Brasil. Acta Botanica Brasilica 25: 255-276.

Cabral EL, Miguel LM \& Viana PL (2012) Two new species of Borreria (Rubiaceae) from Brazil, with new distributional records for Pará state and a key to species with transversally sulcate seeds. Annales Botanici Fennici 49: 209-215.

Delprete PG \& Cortés R (2006) A synopsis of the Rubiaceae of the states of Mato Grosso do Sul, central-western Brazil, with a key to genera, and preliminary species list. Revista de Biologia Neotropical 3: 13-96.

Delprete PG (2007) New combinations and new synonymies in the genus Spermacoce (Rubiaceae) for the flora of Goiás and Tocantins (Brazil) and the flora of the Guianas. Journal Botanical Research Institute of Texas 1: 1023-1030.

Delprete PG (2010) Rubiaceae - Parte 3: Gêneros $\mathrm{S}-\mathrm{W}$, Índices. In: Rizzo JA (coord.) Flora dos estados de Goiás e Tocantins. Vol. 40. IRD/UFG, Universidade Federal de Goiás, Goiânia. Pp. 1098-1610.

Delprete PG, Persson CH, Costa CB, Souza EB, Cabral EL \& Salas RM (2012) Flora do Distrito Federal, Brasil. Vol. 10. Embrapa Recursos Genéticos e Biotecnologia, Brasília. 340p.

Florentin JE, Salas RM, Miguel LM \& Cabral EL (2016) Taxonomía de Spermacoce eryngioides (Rubiaceae) y transferencia de Borreria secc. Pseudodiodia a Spermacoce. Boletín de la Sociedad Argentina de Botánica 51: 551-564.

Gonçalves EG \& Lorenzi H (2011) Morfologia vegetal: organografia e dicionário ilustrado de morfologia das plantas vasculares. $2^{\text {a }}$ ed. Instituto Plantarum, Nova Odessa. 512p.

IBGE - Instituto Brasileiro de Geografia e Estatística (2012) Manual técnico da vegetação brasileira. $2^{\text {a }}$ ed. Disponível em <http://www.ibge.gov.br/ home/geociencias/recursosnaturais/vegetação/ manual_vetação.shtm> Acesso em 22 janeiro 2017.

IPECE - Instituto de Pesquisa e Estratégia Econômica do Ceará (2013) Ceará em números. Disponível em <http://www2.ipece.ce.gov.br/publicacoes/ ceara_em_numeros/2013/completa/Ceara_em_ Numeros_2013.pdf $\geq$. Acesso em 19 junho 2016.

IPNI - The International Plant Names Index (2016) The International Plant Names Index. The Royal Botanic Gardens, Kew. Disponível em <http://www.ipni. org > . Acesso em 19 junho 2016.

Melo AS \& Barbosa MRV (2007) O gênero Borreria G. Mey. (Rubiaceae) na Mata do Buraquinho, João Pessoa, Paraíba. Revista Brasileira de Biociências 5: 627-629.

Miguel, L.M. \& Cabral, E.L. 2013. Borreria krapocarmeniana, a new cryptic species recovered through taxonomic analyses of Borreria scabiosoides and Borreria linoides (Spermacoce, Rubiaceae). Systematic Botany 38: 769-781.

Miguel LM, Souza EB \& Cabral EL (2015) Two new species of Borreria (Spermacoceae, Rubiaceae) from the states of Goiás and Minas Gerais, Brazil. Phytotaxa 201: 149-157.

Mori SA, Silva LAM, Lisboa G \& Coradin L (1989) Manual de manejo do herbário fanerogâmico. Centro de Pesquisa do Cacau, Ilhéus. 44p.

Moro MF, Macedo MB, Moura-Fé MM, Castro ASF \& Costa RC (2015) Vegetação, unidades fitoecológicas e diversidade paisagística do estado do Ceará. Rodriguésia 66: 717-743.

Pire SM (1996) Palynological study of American species of Borreria (Rubiaceae - Spermacoceae). Opera Botanica Belgica 7: 413-423.

Quadros FLF, Bica GS, Damé PRV, Dorow R, Kersting C \& Potter L (2003) Levantamento das pastagens naturais da região de Santa Maria-RS, Brasil. Ciência Rural 33: 921-927.

Radford AE, Dickison WC, Massey JR \& Bell CR (1974) Fundamentals of plant systematics. Harper \& Row, New York. 498p.

Robbrecht E (1988) Tropical woody Rubiaceae. Characteristic features and progressions. Contributions to a new subfamilial classification. Opera Botanica Belgica 1: 1-271.

Souza EB, Miguel LM, Cabral EL, Nepomuceno FAA \& Loiola MIB (2016) Borreria apodiensis (Rubiaceae: Spermacoceae), a new species from Ceará and Rio Grande do Norte, Brazil. Acta Botanica Brasilica 30: 283-289.

Thiers B [continuamente atualizado] Index herbariorum: a global directory of public herbaria and associated staff. New York Botanical Garden's Virtual Herbarium. Disponível em $<$ http://sweetgum.nybg. org/ih/>. Acesso em 19 junho 2016. 


\section{Lista de exsicatas}

Alves AL 17 (8). Amaro R 119 (10). Andrade IM 33 (8). Andrade T s.n. EAC16612 (7). Araújo RS s.n. HUVA 14776 (10). Barros EO 20 (7). Brandão EK 19 (2), 53 (8), 68 (10), 80 (10). Carvalho A s.n. EAC 31776 (2). Castro ASF 2538 (8). Delprete P 6856 (10), 6865 (10), 6891 (8), 6896 (6), 6904 (8), 6909 (8), 6910 (8), 6920 (10), 7179 (8), 7180 (10), 7184 (10), 7185 (8), 7190 (2), 7240 (5), 7244 (7), 7264 (6), 7271 (2), 7272 (2), 7289 (2), 7295 (10), 7298 (10), 7301 (8), 7305 (8), 7306 (8), 7307 (5), 7312 (10), 7321 (8). Djane 01 (10). Dutra LA s.n. HUVA 3557 (7). Fernandes A s.n. EAC 27785 (10). Figueiredo MA s.n. EAC 19776 (7). Figueiredo MF 2381 (2). Lady s.n. EAC 38425 (5). Lima DA 121 (7), 123 (2), 125 (8). Lima-Verde LW 565 (8), 567 (8), 2143 (8), 3013 (10). Linhares KME 59 (2). Marreira EM 3 (8), 94 (5), 169 (7). Martins P s.n. EAC 6599 (8), s.n. EAC 10201 (7), s.n. EAC 11214 (8). Matias LQ 165 (7), 252 (10). Medeiros JBLP 80 (8). Melo E 10275 (8), 10427 (10). Miranda AM 6316 (7). Moro MF 403 (8). Nascimento JEM 90 (8), 230 (5). Nepomuceno FAA 79 (8). Normando LRO 214 (7), 244 (8). Noronha PR s.n. EAC 17187 (8). Nunes E s.n. EAC 11566 (8), s.n. EAC 12685 (2). Oliveira FF 3 (10). Paula-Souza J 10946a (8). Ribeiro IJ 3 (10). Rodrigues AGS s.n. HUVA 3707 (8). Santos FDS 195 (8). Silvio C s.n. EAC 30942 (7). Souza EB s.n. EAC 20210 (2), s.n. EAC 20249 (5), s.n. EAC 21203 (7), s.n. EAC 21204 (7), s.n. EAC 21928 (8), s.n. EAC 22019 (6), s.n. EAC 22021 (6), s.n. EAC 22028 (5), 195 (8), 241 (5), 731 (2), 1746 (8), 1759 (6), 2052 (8), 2073 (2), 2075 (5), 2237 (6), 2487 (8), 2488 (6), 2504 (9), 2517 (8), 2530 (9), 2535 (7), 2550 (2), 2827 (2), 2828 (5), 2862 (10), 2870 (6), 2932 (8), 3118 (7), 3192 (10), 3193 (8), 3277 (7), 3308 (2), 3612 (9), 3647 (9), 4209 (9). Tabosa A 11 (7). Trigueiro E s.n. EAC 30609 (8), 4 (10). 